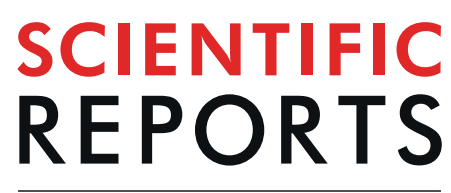

natureresearch

\title{
Bevacizumab improves survival in metastatic colorectal cancer patients with primary tumor resection: A meta-analysis
}

\begin{abstract}
Dedong $\mathrm{CaO}^{1,3^{*}}$, Yongfa Zheng ${ }^{1,3}$, Huilin $\mathrm{Xu}^{2}$, Wei Ge ${ }^{1}$ \& Ximing $\mathrm{Xu}^{1 *}$
It is not well determined whether primary tumor resection is associated with better outcomes in metastatic colorectal cancer ( $m C R C$ ) patients treated with bevacizumab. In this meta-analysis, we aimed to assess the prognostic role of primary tumor resection in $\mathrm{MCRC}$ treated with bevacizumab. Electronic databases including the Cochrane library, Embase, and Pubmed were searched until April 2018. Clinical studies assessing the influence of primary tumor resection on the efficacy of bevacizumab in patients with $\mathrm{mCRC}$ were identified. The primary endpoint was overall survival (OS), and the secondary endpoint was progression-free survival (PFS). Seven studies including $2760 \mathrm{mCRC}$ patients were finally included. The results of the meta-analysis were in favor of bevacizumab to patients with resected primary tumor in terms of OS ( $\mathrm{HR}=0.50,95 \% \mathrm{Cl}: 0.39-0.64 ; p<0.01)$, and PFS (HR $=0.65$, $95 \% \mathrm{Cl}: 0.51-0.81 ; p<0.01)$. Administration of bevacizumab in $\mathrm{mCRC}$ patients with resected primary tumor had a better OS (HR=0.65,95\% $\mathrm{Cl}: 0.56-0.74 ; p<0.01)$, when compared to chemotherapy(CT). Adding bevacizumab to $\mathrm{mCRC}$ patients without resection of primary tumor also had a better OS $(\mathrm{HR}=0.78,95 \% \mathrm{Cl}: 0.65-0.94 ; p<0.01)$ and PFS ( $\mathrm{HR}=0.71,95 \% \mathrm{Cl}: 0.57-0.88 ; p<0.01)$ compared to chemotherapy alone. In conclusion, $\mathrm{mCRC}$ patients with resected primary tumor have better survival than those without surgery of primary tumor when treated with bevacizumab. Primary tumor resection status should be taken into consideration when using bevacizumab in $\mathrm{mCRC}$.
\end{abstract}

Colorectal cancer (CRC) is one of the most common tumors, and 20\% 25\% of these patients are diagnosed as stage IV disease ${ }^{1}$. CRC patients with unresectable metastases have a limited median survival around 5 months if only treated with best supportive care ${ }^{2}$. Due to effective treatment strategies, the survival of mCRC has been extensively improved. Bevacizumab, one of the molecular targeted drugs, brings survival advantage in metastatic CRC (mCRC) as proved by recent pieces of evidence ${ }^{3,4}$. However, not all the mCRC patients could get clinical benefits from bevacizumab. How to predict the efficacy of bevacizumab in $\mathrm{mCRC}$ is still under investigating ${ }^{5}$.

Previously, several studies and reviews ${ }^{6-8}$ have shown that primary tumor resection is associated with better outcomes in mCRC patients after treatment of chemotherapy or radiotherapy. Ishihara et al. ${ }^{6}$ reported that primary tumor resection significantly improved cancer-specific survival $(\mathrm{HR}=0.46, \mathrm{p}<0.01)$. The study of Tong ${ }^{8}$ also concluded that surgery of primary cancer might improve the survival of metastatic rectal cancer patients. However, whether primary tumor resection also has the same role in predicting the efficacy of bevacizumab, it has not been well investigated.

In recent years, there are accumulating clinical studies ${ }^{9-15}$ that assessing the efficacy of bevacizumab is influenced by primary tumor resection or not in mCRC. These studies suggested that surgery of primary tumor was associated with better survival when managed with bevacizumab. Although positive results emerged, an agreement about the impact of primary tumor resection on bevacizumab has not yet been reached ${ }^{3,16,17}$. These studies are not capable of providing encouraging evidence for guiding use of bevacizumab or predicting efficacy of bevacizumab based on primary tumor resection in mCRC.

${ }^{1}$ Department of Oncology, RenMin Hospital of Wuhan University, Jiefang Road \#238 Wuchang District, Wuhan, 430000, China. ${ }^{2}$ Department of Oncology, The Fifth hospital of Wuhan, Xianzheng Street \#122 Hanyang District, Wuhan, 430000, China. ${ }^{3}$ These authors contributed equally: Dedong Cao and Yongfa Zheng. *email: caodedong123@163.com; doctorxu120@aliyun.com 
Thus, we identified clinical trials assessing the impact of primary tumor resection on the efficacy of bevacizumab in mCRC patients and performed a meta-analysis by using HRs of resection versus no resection for survival in mCRC patients after bevacizumab treatment. With this purpose, we expected to establish an evidence-based relationship between primary tumor resection and efficacy of bevacizumab.

\section{Methods}

Search strategy. The Preferred Reporting Items for Systematic Reviews and Meta-Analyses guidelines(PRISMA $)^{18}$ was applied during the process of this meta-analysis. There was no registration information for this study. Electronic databases including the Cochrane library, Embase, and Pubmed were searched to identify clinical trials assessing the impact of resection versus no resection of primary tumor on the survival of mCRC patients with a deadline of April 2018. The search terms of ("colonic neoplasm", or "tumor, colorectal", or "carcinoma, colorectal", or "colorectal cancer"), ("survival", or "overall survival", or "progression-free survival", or "OS”, or "PFS”), (“bevacizumab" or "Avastin", or "anti-VEGF humanized monoclonal antibody"), and ("primary tumor resection" or "primary tumor surgery" or "resected primary tumor" or "original tumor resection" or "original tumor surgery") were used in different combinations during the search. The "similar articles" indicated by Pubmed was also reviewed to achieve a maximum inclusion. There was no language limitation in this study. Conference abstracts were also included if sufficient data was provided.

Study selection, inclusion and exclusion criteria. The primary endpoint was overall survival (OS), while the secondary was progression-free survival (PFS). Clinical trials evaluating the relationship between primary tumor resection and benefits of bevacizumab on survival in mCRC patients were included. The inclusion criteria were: (1) clinical studies that included mCRC patients, either randomized controlled trials or retrospective studies with sufficient baseline and endpoint information; (2) mCRC patients treated with bevacizumab in combination with or without traditional chemotherapy; (3) clear definition of OS and PFS; (4)Comparing impact of primary tumor resection versus no resection on OS and/or PFS in mCRC treated with bevacizumab; (5) sufficient data for extracting hazard ratio(HR) and its 95\% confidence interval(CI) in term of OS and PFS directly or indirectly(survival curve provided). Reviews, animal studies, treatment guidelines, case reports, letters, comments, and meta-analyses were excluded. Studies without sufficient data to calculate the HRs and associated CIs were also discarded.

Data extraction and quality assessment. The work of data extraction was conducted by two reviewers (Dedong Cao, Huilin $\mathrm{Xu}$ ), independently. A third reviewer was invited if there were any disagreements during the process of data extraction. Baseline characteristics such as first author, publication year, number of included patients, gender, age, region, treatment line and dose of bevacizumab, and chemotherapy were collected. Primary and secondary endpoints including OS and PFS were also extracted. The reported methods ${ }^{19,20}$ were applied to obtain HRs and related CIs if they were not directly presented in the included studies. The first author and publication year were used to identify included studies.

The Newcastle Ottawa Scale (NOS) that recommended by the Cochrane non-randomized studies methods working group was applied to evaluate the quality of included studies ${ }^{21}$. In brief, NOS had three broad perspectives and they were selection, comparability, and outcome. There were four, one and three numbered items to assess the quality of retrospective studies, respectively. A study can be awarded a maximum of one star for each numbered item within the Selection and Outcome categories. A maximum of two stars can be given for Comparability $^{22}$. In this study, we defined a high-quality study if it met five or more NOS criteria item. This work was finished by Dedong Cao and Huilin Xu, independently. Another researcher was involved if a discrepancy about quality evaluation of a certain study emerged.

Statistical analysis. To perform the statistical analysis, we used the RevMan 5.3 and STATA 12 software from the Cochrane Collaboration. The endpoints were OS and PFS. The HRs and relevant 95\% CIs of resection versus no resection of primary tumor for assessing the effect of resection on OS and PFS in bevacizumab treated mCRC were extracted from full-text or survival curves. The logarithms of HRs (logHRs) along with the standard error (SE) were calculated to conduct the combined analysis. Before performing the synthesized analysis, $\mathrm{I}^{2}$ statistics by Higgins ${ }^{23}$ was used to detect the potential heterogeneity between included studies. The percentage of variation across studies that caused by heterogeneity rather than chance was described by $\mathrm{I}^{2}$ statistic ${ }^{23}$. The significance of heterogeneity indicated by $\mathrm{I}^{2}$ statistics was classified into three degrees as previously described ${ }^{23}$. In brief, it was considered as low, moderate, or high heterogeneity if the $\mathrm{I}^{2}<50 \%, 50 \%<\mathrm{I}^{2} \leq 75 \%$, and $\mathrm{I}^{2}>75 \%$, respectively. For moderate and high risk of heterogeneity, the random effect model (Mantel-Haenszl) was applied. Otherwise, the fixed effect model (Mantel-Haenszl) was used. For analysis with moderate and high risk of heterogeneity, the subgroup analysis and sensitivity analysis were introduced to find the possible sources of differences. The items used to perform the subgroup analysis were region, treatment line of bevacizumab, and dose of bevacizumab. If the combined $\mathrm{HR}<1$, it indicated a better efficacy of bevacizumab for the primary tumor resected mCRC patients. The funnel plot was used to check the risk of publication bias. All statistical tests were two-sided, and a statistical significance was achieved if the $\mathrm{p}<0.05$.

Statement of significance. Although bevacizumab prolonged the survival of colorectal cancer (CRC) patients, it is still difficult to predict whether the survival of metastatic patients can be significantly improved by bevacizumab. Recently, there is a debate about the impact of primary tumor resection (PTR) on efficacy of bevacizumab in metastatic CRC (mCRC). While some researchers suggested a positive role of PTR on predicting survival advantage of bevacizumab, other investigators found negative results. Therefore, we used meta-analysis to determine the effects of PTR versus no PTR in mCRC patients after treatment with bevacizumab, aimed to establish a prognostic role of PTR in predicting efficacy of bevacizumab, and gave reliable recommendation on 


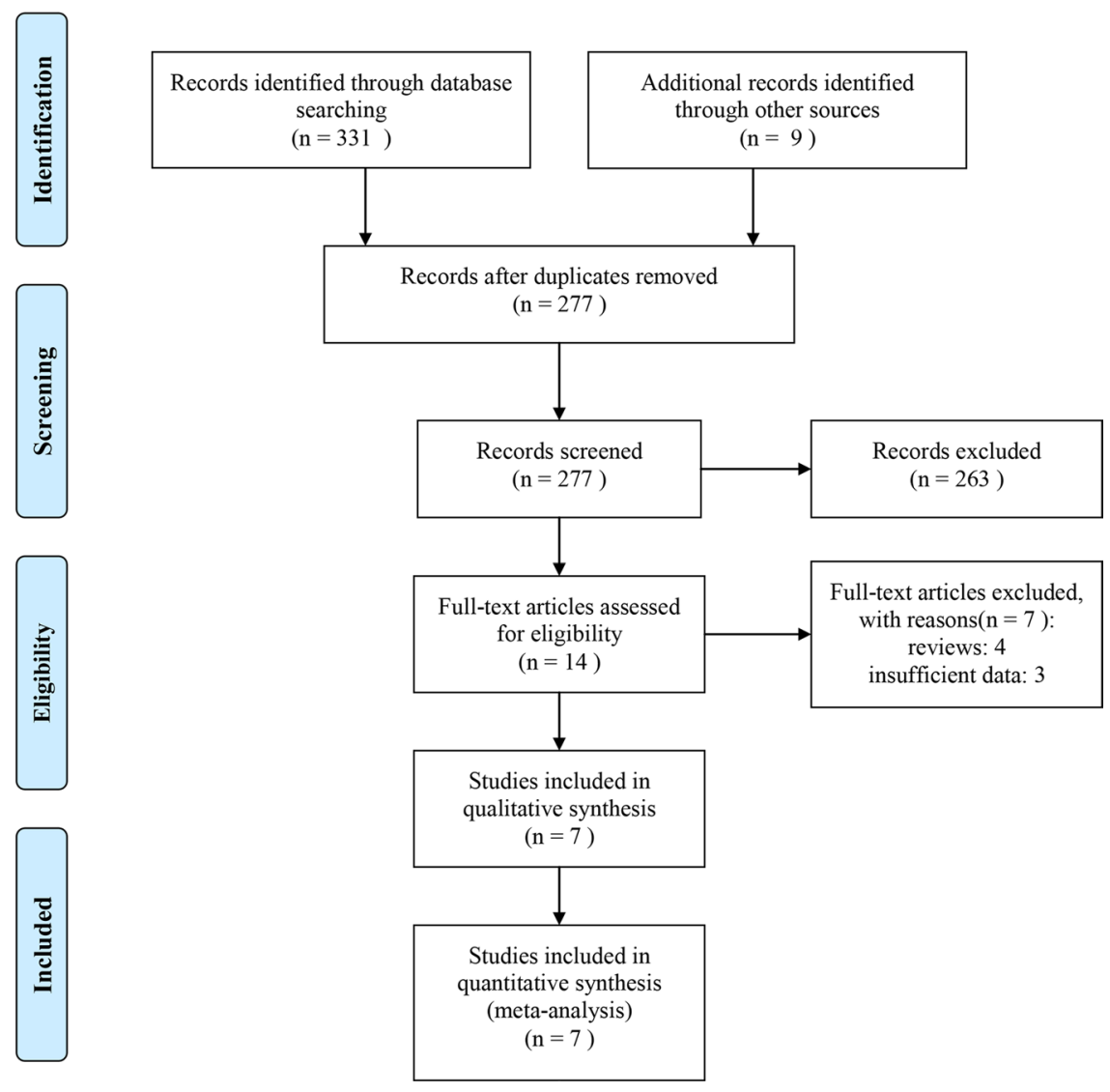

Figure 1. Flow diagram of searching for eligible studies.

surgical treatment of primary tumor if possible. Our findings suggested that mCRC patients with PTR had a significantly better survival after bevicazumab treatment. These findings indicated PTR can be recommended as a prognostic factor of good efficacy of bevacizumab in mCRC patients.

\section{Results}

Search results. After a comprehensive search, a number of 340 studies were retrieved. 63 of them were duplicates and discarded. 277 studies were screened with title and abstract, and 263 of them were excluded as they were animal studies, reviews, case-report, guidelines, commentary, and meeting abstracts with limited data. The left 14 studies were further reviewed by full-text, and half of them were excluded as they were lack of sufficient data and reviews. Finally, seven clinical studies ${ }^{2,3,11,14,16,17,24}$ were regarded as eligible and included for the final quantitative synthesis. The detailed study selection process is presented in Fig. 1.

Baseline characteristics of included studies. Among seven included studies, five $\mathrm{e}^{3,11,14,16,24}$ of them were retrospective trials and $\mathrm{two}^{2,17}$ were prospective studies published from 2011 to 2016 . The median age ranged from 52 to 66 . The most used chemotherapies were fluorouracil, oxaliplatin-based or irinotecan-based regimen (IFL, bolus 5FU+ irinotecan; FOLFIRI, infusional 5FU + irinotecan; XELOX,capecitabine + oxaliplatin; FOLFOX, 5FU + oxaliplatin + leucovorin). The dose of bevacizumab ranged from $5 \mathrm{mg} / \mathrm{kg}$ to $7.5 \mathrm{mg} / \mathrm{kg}$, and the treatment line ranged from the first line to third or more line. Some the primary tumor site data were not available(NA) from some of the included studies. Adverse events(AEs) were also reported in some of the studies. The individual OS reported by each included study ranged from 20.7 to 29.8 months in the resection group, whereas they were from 13.4 to 20 months in the no resection group (Table 1). The PFS was between 9 and 10.8 months in the resection group, while they were between 7 and 9 months in no resection group. Few of the included trials reported HR directly, while HRs were calculated from survival curves from other studies ${ }^{2,3,11,14,16,17}$, indirectly. The method was mentioned in the statistical analysis section. The baseline characteristics of the included studies are presented in Table 1.

The quality assessment results of the included studies are summarized in Table 2. All of the eligible studies were regarded as moderate or high quality as they met most of the criteria of the NOS.

Results of meta-analysis. OS. To evaluate the role of primary tumor resection on OS in mCRC patients who were treated with bevacizumab, the HRs of resection versus no resection were extracted from all of the included studies $2,3,11,14,16,17,24$. As indicated by the heterogeneity test $\left(\mathrm{I}^{2}=89 \%\right)$, the random effect model was used. There were 1220 patients underwent primary tumor resection and 618 cases without resection. The included 


\begin{tabular}{|c|c|c|c|c|c|c|c|c|c|c|c|c|c|c|c|c|c|c|}
\hline \multirow[b]{2}{*}{ Authors } & \multirow[b]{2}{*}{ Year } & \multirow[b]{2}{*}{$\mathrm{N}$} & \multicolumn{2}{|c|}{ Participants } & \multicolumn{2}{|c|}{ Age(year) } & \multicolumn{2}{|l|}{ Sex } & \multicolumn{2}{|l|}{ Treatment } & \multirow{2}{*}{\begin{tabular}{|l|}
$\begin{array}{l}\text { Treatment } \\
\text { line }\end{array}$ \\
Bev
\end{tabular}} & \multicolumn{2}{|c|}{ Primary tumor } & \multirow[b]{2}{*}{ Outcomes } & \multicolumn{2}{|c|}{ OS(months) } & \multicolumn{2}{|c|}{$\begin{array}{l}\text { PF } \\
\text { S(months) }\end{array}$} \\
\hline & & & PTR & IPT & PTR & IPT & male & female & CT & $\begin{array}{l}\text { Bevacizumab } \\
\text { (Bev) }\end{array}$ & & Colon & Rectum & & PTR & IPT & PTR & IPT \\
\hline Sabine & 2011 & 448 & 289 & 159 & \begin{tabular}{|l}
62 \\
$(35-80)$
\end{tabular} & $60(31-78)$ & 260 & 188 & XELOX & $\begin{array}{l}7.5 \mathrm{mg} / \mathrm{kg} \\
\text { every } 3 \text { weeks }\end{array}$ & First & 199 & 84 & $\begin{array}{l}\text { OS, PFS, } \\
\text { AEs }\end{array}$ & 20.7 & 13.4 & 10.5 & 7.8 \\
\hline Bulent & 2013 & 99 & 53 & 46 & $\begin{array}{l}55 \\
(28-73)\end{array}$ & $52(23-74)$ & 56 & 43 & $\begin{array}{l}\text { FOLFIRI/ } \\
\text { XELOX/IFL }\end{array}$ & $\begin{array}{l}\text { Median } \\
\text { cumulative } \\
\text { bevacizumab } \\
\text { doses were } \\
\text { similar } \\
\text { between } \\
\text { the groups: } \\
\text { non-surgery } \\
\text { group 4400 mg } \\
\text { (range, } \\
1200-12800 \text { ) } \\
\text { vs. surgery } \\
\text { group 4800 mg } \\
\text { (range, } \\
\text { 1600-9200) }\end{array}$ & Multiple line & 65 & 34 & $\begin{array}{l}\text { OS, PFS, } \\
\text { AEs }\end{array}$ & 23 & 17 & 9 & 7 \\
\hline Francois & 2014 & 409 & 193 & 41 & $\begin{array}{l}66 \\
(24-90)\end{array}$ & $65(35-86)$ & NA & NA & $\begin{array}{l}\text { FOLFIRI/ } \\
\text { XELOX/IFL }\end{array}$ & $\begin{array}{l}\text { Either } 5 \mathrm{mg} / \mathrm{kg} \\
\text { every } 2 \text { weeks } \\
\text { or } 7.5 \mathrm{mg} / \mathrm{kg} \\
\text { every } 3 \text { weeks }\end{array}$ & Multiple line & 184 & 48 & OS & 27 & 20 & NA & NA \\
\hline Kodaz & 2015 & 93 & 46 & 47 & \begin{tabular}{|l|}
60 \\
$(30-82)$
\end{tabular} & $61(27-84)$ & 52 & 41 & $\begin{array}{l}\text { FOLFIRI/ } \\
\text { Folfox based }\end{array}$ & $\begin{array}{l}\text { Used as } \\
\text { suggested dose }\end{array}$ & Multiple line & NA & NA & OS,PFS & 25 & 16 & 9 & 9 \\
\hline Lee & 2016 & 1204 & 357 & 200 & $\begin{array}{l}66 \\
(25-92)\end{array}$ & $62(27-89)$ & 220 & 337 & $\begin{array}{l}\text { FOLFIRI/ } \\
\text { Oxaliplatin- } \\
\text { based/ } \\
\text { Irinotecan- } \\
\text { based }\end{array}$ & $\begin{array}{l}7.5 \mathrm{mg} / \mathrm{kg} \\
\text { every } 3 \text { weeks }\end{array}$ & Multiple line & 381 & 148 & $\begin{array}{l}\text { OS, PFS, } \\
\text { AEs }\end{array}$ & 24.4 & 20 & 10.8 & 8.5 \\
\hline Mathilde & 2016 & 316 & 164 & 52 & $\begin{array}{l}65 \\
(31-83)\end{array}$ & $63(22-87)$ & 138 & 78 & $\begin{array}{l}\text { Oxaliplatin- } \\
\text { based/ } \\
\text { Irinotecan- } \\
\text { based }\end{array}$ & $\begin{array}{l}\text { Either } 5 \mathrm{mg} / \mathrm{kg} \\
\text { every } 2 \text { weeks } \\
\text { or } 7.5 \mathrm{mg} / \mathrm{kg} \\
\text { every } 3 \text { weeks }\end{array}$ & Multiple line & 158 & 54 & $\begin{array}{l}\text { OS, PFS, } \\
\text { AEs }\end{array}$ & 29.8 & 18.2 & 9.7 & 8.1 \\
\hline Wang & 2016 & 191 & 118 & 73 & $\begin{array}{l}57 \\
(22-77)\end{array}$ & $58(22-73)$ & 108 & 83 & $\begin{array}{l}\text { FOLFIRI/ } \\
\text { XELOX/ } \\
\text { FOLFOX }\end{array}$ & $\begin{array}{l}\text { Either } 5 \mathrm{mg} / \mathrm{kg} \\
\text { every } 2 \text { weeks } \\
\text { or } 7.5 \mathrm{mg} / \mathrm{kg} \\
\text { every } 3 \text { weeks }\end{array}$ & First & 115 & 76 & $\begin{array}{l}\text { OS, PFS, } \\
\text { AEs }\end{array}$ & 22.5 & 17.8 & 10 & 7.8 \\
\hline
\end{tabular}

Table 1. Baseline characteristics of $\mathrm{mCRC}$ patients with primary tumor resection(PTR) versus intact primary tumor(IPT).

\begin{tabular}{|l|l|l|l|l|}
\hline First author & Year & Selection & Comparability & Outcome \\
\hline Sabine & 2011 & $\star \star \star$ & $\star \star$ & $\star \star \star$ \\
\hline Bulent & 2013 & $\star \star \star$ & $\star \star$ & $\star \star \star$ \\
\hline Francois & 2014 & $\star \star$ & $\star \star$ & $\star \star \star$ \\
\hline Kodaz & 2015 & $\star \star \star$ & $\star \star$ & $\star \star \star$ \\
\hline Lee & 2016 & $\star \star \star$ & $\star \star$ & $\star \star \star$ \\
\hline Mathilde & 2016 & $\star \star \star$ & $\star \star$ & $\star \star \star$ \\
\hline Wang & 2016 & $\star \star \star$ & $\star$ & $\star \star$ \\
\hline
\end{tabular}

Table 2. Quality assessment of included studies by NOS. Note: Retrospective studies were assessed by NOS method. A study can be awarded a maximum of one star for each numbered item within the Selection and Outcome categories. A maximum of two stars can be given for Comparability, according to the instruction of NOS.

patients were all treated with bevacizumab. The results of meta-analysis showed that the risk of mortality in primary tumor resected mCRC patients was significantly reduced after treatment of bevacizumab $(\mathrm{HR}=0.50$; 95\%CI: $0.39,0.64 ; \mathrm{p}<0.00001$ ), compared to those without primary tumor resection (Fig. 2A).

As there was significant heterogeneity, the subgroup analysis was introduced based on the factors of region (Supplemental Fig. 1A), high-dose (7.5 mg/kg every three-week) of bevacizumab (Supplemental Fig. 1B), and treatment line of bevacizumab (Supplemental Fig. 1C). The dose and treatment line of bevacizumab varied between included studies and high-dose subgroup of OS had a low heterogeneity $\left(\mathrm{I}^{2}=0 \%\right)$. The sensitivity analysis revealed that the combined HR for OS was not significantly changed after exclusion of each included studies (Supplemental Fig. 2).

Next, we extracted the HRs of bevacizumab + chemotherapy versus chemotherapy alone for OS in primary tumor resected mCRC (Fig. 3A) and no resection (Fig. 3B) patients. Three studies ${ }^{11,14,17}$ provided specific data of interest. In primary tumor resected population, the administration of bevacizumab was associated with significantly improved OS when compared with chemotherapy $\left(\mathrm{I}^{2}=0 \%, \mathrm{HR}=0.65 ; 95 \% \mathrm{CI}: 0.56,0.74 ; \mathrm{p}<0.00001\right)$. In patients with intact primary tumor, most of the included studies showed there were no significant benefits on OS when using bevacizumab ( $\mathrm{p}>0.05)$. However, the pooled OS was significantly increased after adding bevacizumab to chemotherapy $\left(\mathrm{I}^{2}=9 \%, \mathrm{HR}=0.78 ; 95 \% \mathrm{CI}: 0.65,0.94 ; \mathrm{p}=0.009\right)$. The result from Lee et al. ${ }^{17}$ contributed most to this improvement in OS (Supplemental Table 1). 


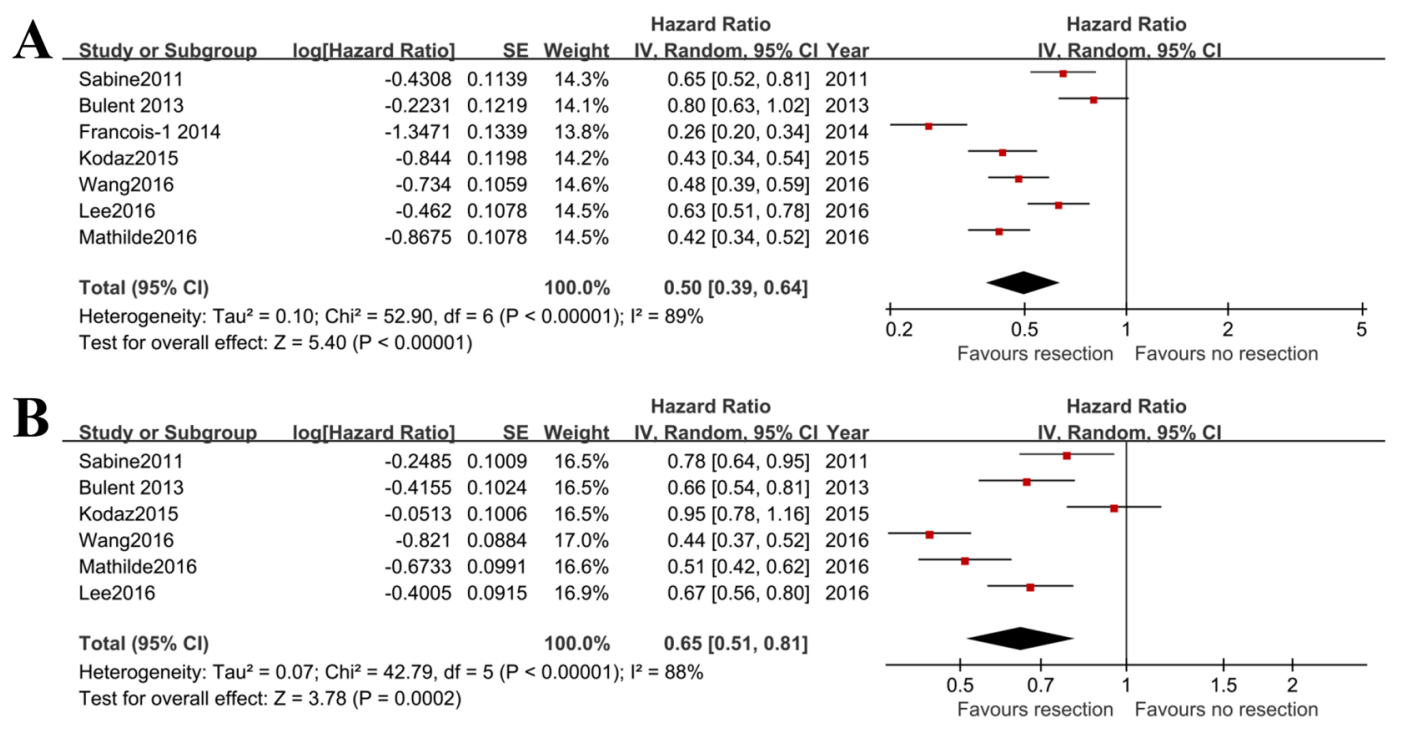

Figure 2. Pooled overall survival and progression free survival outcomes in mCRC patients with primary tumor resection versus no resection after treatment of bevacizumab. (A) combined HR of resection $(n=1220)$ versus no resection $(n=618)$ of primary tumor for assessing effect of bevacizumab on OS; (B) combined HR of resection $(n=1027)$ versus no resection $(n=577)$ of primary tumor for assessing effect of bevacizumab on PFS.

PFS. A meta-analysis of PFS between resection versus no resection of primary tumor in bevacizumab treated mCRC was performed. Six studies ${ }^{2,3,11,16,17,24}$ reported relevant HR or survival curve. The random effect model was used as there was a high risk of heterogeneity $\left(\mathrm{I}^{2}=88 \%\right)$. There were 1027 patients had the primary tumor resection and 577 patients with no resection of the primary tumor. Bevacizumab was administrated to all the included patients. Results showed that the risk of progression was decreased by $0.35(\mathrm{HR}=0.65 ; 95 \% \mathrm{CI}$ : 0.51 , $0.81 ; \mathrm{p}=0.0002)$ in resected patients after receiving bevacizumab, compared to no resection of primary tumor (Fig. 2B).

To assess the influence of bevacizumab on PFS in primary tumor resected and no resected patients, the data of interest was extracted from two studies ${ }^{11,17}$. The fixed effect model was used for these two meta-analyses (Fig. 3C,D). Adding bevacizumab to chemotherapy could statistically improve PFS in mCRC patients either with $(\mathrm{HR}=0.68 ; 95 \% \mathrm{CI}: 0.56,0.83 ; \mathrm{p}=0.0001)$ or without $(\mathrm{HR}=0.71 ; 95 \% \mathrm{CI}: 0.57,0.88 ; \mathrm{p}=0.002)$ primary tumor resection (Supplemental Table 1).

Publication bias assessment. To assess the potential publication bias, the funnel plot along with the Begg's test and Egger's test were used. As illustrated by Supplemental Fig. 2, the funnel chart was symmetrical. The Begg's test $(\mathrm{p}=1.0)$ and Egger's test $(\mathrm{p}=0.416)$ suggested there was no significant publication bias with regards to OS.

\section{Discussion}

Whether primary tumor resection could affect the survival outcome of mCRC patients treated with bevacizumab, it was still in debate. To address this concern, we performed this meta-analysis by including individual data from seven clinical studies that assessing the impact of primary tumor resection on survival benefit of bevacizumab in mCRC patients. The results of meta-analysis showed that mCRC patients with resected primary tumor had a significantly better OS and PFS compared to those without resection of primary tumor. In addition, when compared with chemotherapy alone, the addition of bevacizumab to chemotherapy also significantly improved OS and PFS in primary tumor resected $\mathrm{mCRC}$ patients. The combined effect of bevacizumab on OS in mCRC patients without resected primary tumor was positive. However, this evidence was not so convincing. These findings suggested that primary tumor resection was associated with significantly better efficacy of bevacizumab in terms of OS and PFS, and it could be used as a prognostic factor of bevacizumab in mCRC patients (Supplemental Table 1). To our knowledge, this is the first meta-analysis evidence to show the role of primary tumor resection on survival of mCRC patients treated with bevacizumab.

The present study found that the efficacy of bevacizumab was influenced by the resection status of primary tumor in mCRC patients. Patients with resected primary tumor could benefit most from bevacizumab. As shown above, after treating with bevacizumab, the individual OS reported in primary tumor resected patients ranged from 20.7 months to 29.8 months, and they were from 13.4 months to 20 months in no resection patients. The combined median OS was 24.6 months for resection and 17.5 months for no resection, with a difference of 7.1 months. The difference of median PFS was 1.8 months in term of resection versus no resection. The pooled results demonstrated a longer OS after bevacizumab treatment in resection group than that of the no resection group. In addition, in patients with primary tumor resection, the OS was also significantly improved after adding bevacizumab to chemotherapy versus chemotherapy alone. The subgroup analysis suggested that the impact of primary tumor resection on OS was not statistically changed by region, treatment line and dose of bevacizumab, suggesting primary tumor resection was a reliable indicator for better outcomes of bevacizumab. 


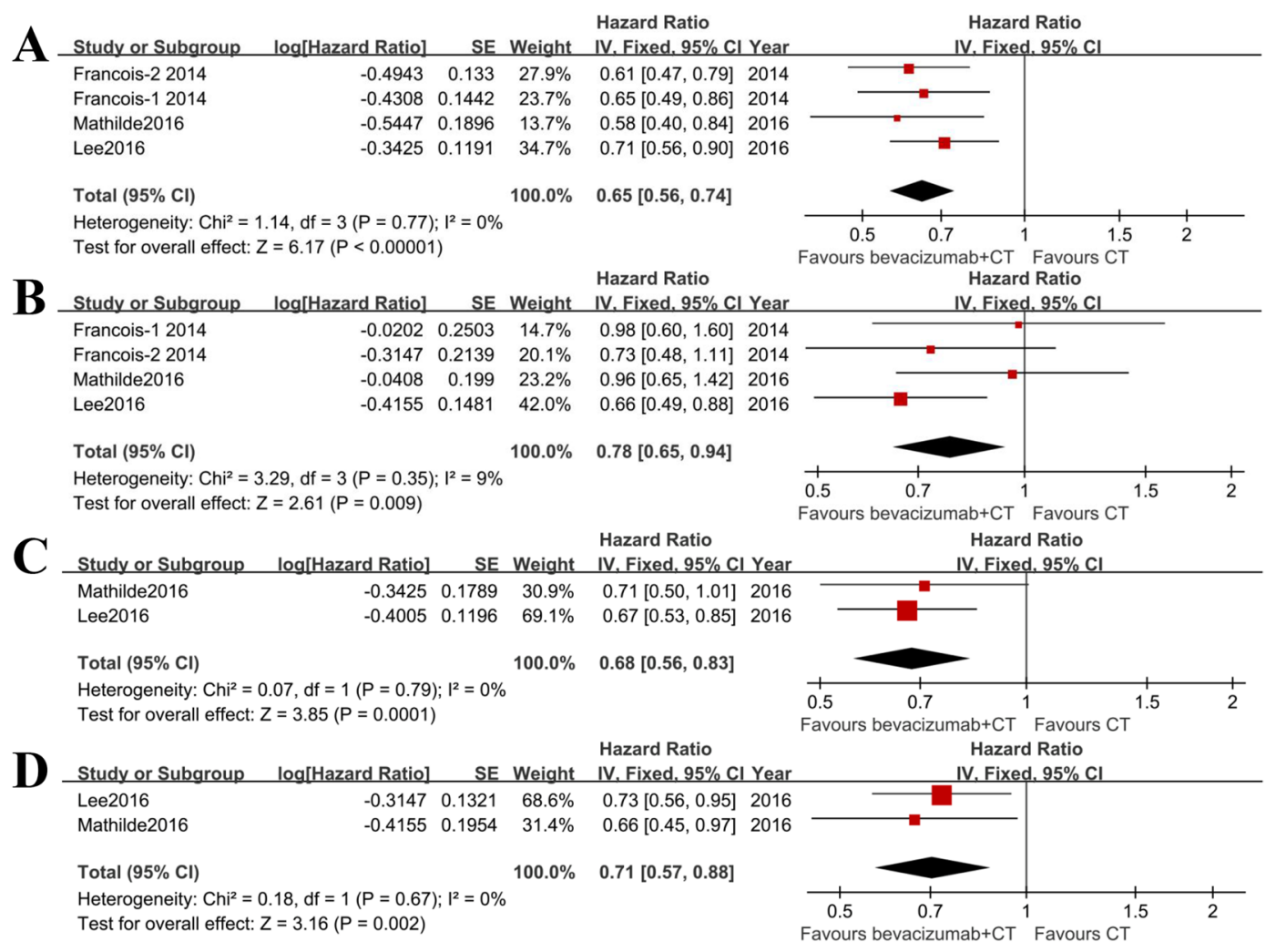

Figure 3. Combined HR to evaluate benefits of adding bevacizumab to chemotherapy versus chemotherapy alone in mCRC patients with or without primary tumor resection. (A) OS of bevacizumab plus chemotherapy versus chemotherapy alone in primary tumor resected patients $(n=847)$; (B) OS of bevacizumab plus chemotherapy versus chemotherapy alone in patients without resection of primary tumor $(n=424)$; (C) PFS of bevacizumab plus chemotherapy versus chemotherapy alone in primary tumor resected patients $(n=521)$; (D) PFS of bevacizumab plus chemotherapy versus chemotherapy alone in patients without resection of primary tumor $(\mathrm{n}=252)$.

In most current guidelines, the role of primary tumor resection in mCRC patients has not been well established ${ }^{25,26}$. For stage IV CRC, multiple factors should be taken into consideration before making a treatment decision. The guidelines of EURECCA and ESMO do not suggest resecting primary tumor in asymptomatic mCRC patients that beyond resection possibilities ${ }^{25}$. These recommendations are established based on the evidence provided by Cirocchi et al. ${ }^{27}$. That meta-analysis found that resection of primary tumor in asymptomatic mCRC who were treated with chemo/radiotherapy was not associated with a consistent improvement in $\mathrm{OS}^{27}$. However, recent meta-analyses ${ }^{26,28-31}$ demonstrate that primary tumor resection may provide a survival benefit. These studies assessed the role of primary tumor resection on efficacy of chemotherapy or radiotherapy, but not bevacizumab. Therefore, we perform this meta-analysis to address whether the efficacy of bevacizumab is also influenced by primary tumor resection. A positive link between resection of primary tumor and effects of bevacizumab on survival was confirmed by our findings. Several clinical indications are concluded from the present meta-analysis. Clinically, the primary tumor should be resected if possible. And the resection status can be used as a prognostic factor to predict the beneficial effects of bevacizumab containing regimen. It is also encouraged to adding bevacizumab to chemotherapy in original tumor resected mCRC patients.

There are several limitations in our meta-analysis. First, high risk of heterogeneity existed among the included trials. The differences of baseline characteristics, chemotherapy regimen, treatment line and dose of bevacizumab, sites of primary tumor, numbers and sites of metastasis may contribute to the significant heterogeneity. Second, though all of the studies were considered as moderate or high quality, only a few of them reported HRs of primary and secondary endpoints, directly. Data from the survival curve had to be extracted to calculate the HR, indirectly. In this condition, the strength of our findings is hampered due to the less reliable HR. Even with these shortcomings, our results still provide objective evidence about the relationship between primary tumor resection and efficacy of bevacizumab.

In conclusion, this meta-analysis suggests that mCRC patients with resected primary tumor have better survival when managed with bevacizumab. Randomized controlled trials are needed to confirm our findings.

Received: 18 June 2018; Accepted: 8 December 2019;

Published online: 30 December 2019 


\section{References}

1. Aran, V., Victorino, A. P., Thuler, L. C. \& Ferreira, C. G. Colorectal Cancer: Epidemiology, Disease Mechanisms and Interventions to Reduce Onset and Mortality. Clinical colorectal cancer, https://doi.org/10.1016/j.clcc.2016.02.008 (2016).

2. Wang, Z. et al. Primary Tumour Resection Could Improve the Survival of Unresectable Metastatic Colorectal Cancer Patients Receiving Bevacizumab-Containing Chemotherapy. Cellular Physiology and Biochemistry 39, 1239-1246, https://doi. org/10.1159/000447829 (2016).

3. Cetin, B. et al. Bevacizumab-containing chemotherapy is safe in patients with unresectable metastatic colorectal cancer and a synchronous asymptomatic primary tumor. Japanese journal of clinical oncology 43, 28-32, https://doi.org/10.1093/jjco/hys175 (2013).

4. Wasserman, D. W. et al. Bevacizumab (Bev)-based therapy for patients (pts) with colorectal cancer (CRC): McGill University and Segal Cancer Centre experience. Journal of Clinical Oncology 29 (2011).

5. Custodio, A. et al. Molecular markers to predict outcome to antiangiogenic therapies in colorectal cancer: current evidence and future perspectives. Cancer treatment reviews 39, 908-924, https://doi.org/10.1016/j.ctrv.2013.02.004 (2013).

6. Ishihara, S. et al. Benefit of primary tumor resection in stage IV colorectal cancer with unresectable metastasis: a multicenter retrospective study using a propensity score analysis. International journal of colorectal disease 30, 807-812, https://doi.org/10.1007/ s00384-015-2228-4 (2015).

7. Furuhata, T. et al. Oncological benefit of primary tumor resection with high tie lymph node dissection in unresectable colorectal cancer with synchronous peritoneal metastasis: a propensity score analysis of data from a multi-institute database. International journal of clinical oncology 20, 922-927, https://doi.org/10.1007/s10147-015-0815-6 (2015).

8. Tong, D., Liu, F., Li, W. \& Zhang, W. The impacts of surgery of the primary cancer and radiotherapy on the survival of patients with metastatic rectal cancer. Oncotarget 8, 89214-89227, https://doi.org/10.18632/oncotarget.19157 (2017).

9. Shida, D. et al. Prognostic Impact of R0 Resection and Targeted Therapy for Colorectal Cancer with Synchronous Peritoneal Metastasis. Annals of surgical oncology 25, 1646-1653, https://doi.org/10.1245/s10434-018-6436-3 (2018).

10. Lim, C. et al. Bevacizumab improves survival in patients with synchronous colorectal liver metastases provided the primary tumor is resected first. Clinical and Translational Oncology, 1-6, https://doi.org/10.1007/s12094-018-1858-8 (2018).

11. Cabart, M. et al. Bevacizumab Efficacy Is Influenced by Primary Tumor Resection in First-Line Treatment of Metastatic Colorectal Cancer in a Retrospective Multicenter Study. Clinical colorectal cancer 15, e165-e174, https://doi.org/10.1016/j.clcc.2016.04.009 (2016).

12. Ahmed, S. et al. Regional Lymph Nodes Status and Ratio of Metastatic to Examined Lymph Nodes Correlate with Survival in Stage IV Colorectal Cancer. Annals of surgical oncology 23, 2287-2294, https://doi.org/10.1245/s10434-016-5200-9 (2016).

13. Ling, J. et al. Primary tumor resection related to better outcome in Chinese metastatic colorectal cancer patients using bevacizumab. European Surgery - Acta Chirurgica. Austriaca 47, S71-S72, https://doi.org/10.1007/s10353-015-0305-0 (2015).

14. Ghiringhelli, F. et al. Bevacizumab efficacy in metastatic colorectal cancer is dependent on primary tumor resection. Annals of surgical oncology 21, 1632-1640, https://doi.org/10.1245/s10434-013-3463-y (2014).

15. De Mestier, L. et al. Is primary tumor resection associated with a longer survival in colon cancer and unresectable synchronous metastases? A 4-year multicentre experience. European Journal of Surgical Oncology 40, 685-691, https://doi.org/10.1016/j. ejso.2014.02.236 (2014).

16. Kodaz, H. et al. Impact of bevacizumab on survival outcomes in primary tumor resected metastatic colorectal cancer. Medical oncology (Northwood, London, England) 32, 441, https://doi.org/10.1007/s12032-014-0441-6 (2015).

17. Lee, B. et al. The impact of bevacizumab in metastatic colorectal cancer with an intact primary tumor: Results from a large prospective cohort study. Asia-Pacific journal of clinical oncology 13, 314-321, https://doi.org/10.1111/ajco.12639 (2017).

18. Moher, D., Liberati, A., Tetzlaff, J., Altman, D. G. \& Group, P. Preferred reporting items for systematic reviews and meta-analyses: the PRISMA statement. International journal of surgery 8, 336-341, https://doi.org/10.1016/j.ijsu.2010.02.007 (2010).

19. Parmar, M. K., Torri, V. \& Stewart, L. Extracting summary statistics to perform meta-analyses of the published literature for survival endpoints. Statistics in medicine 17, 2815-2834 (1998).

20. Williamson, P. R., Smith, C. T., Hutton, J. L. \& Marson, A. G. Aggregate data meta-analysis with time-to-event outcomes. Statistics in medicine 21, 3337-3351, https://doi.org/10.1002/sim.1303 (2002).

21. Higgins, J. P. T. \& Sally Green, E. Cochrane handbook for systematic reviews of interventions. Chichester: Wiley-Blackwell 5 (2008).

22. Stang, A. Critical evaluation of the Newcastle-Ottawa scale for the assessment of the quality of nonrandomized studies in metaanalyses. European journal of epidemiology 25, 603-605, https://doi.org/10.1007/s10654-010-9491-z (2010).

23. Higgins, J. P., Thompson, S. G., Deeks, J. J. \& Altman, D. G. Measuring inconsistency in meta-analyses. BMJ 327, 557-560, https:// doi.org/10.1136/bmj.327.7414.557 (2003).

24. Venderbosch, S. et al. Prognostic value of resection of primary tumor in patients with stage IV colorectal cancer: retrospective analysis of two randomized studies and a review of the literature. Annals of surgical oncology 18, 3252-3260, https://doi.org/10.1245/ s10434-011-1951-5 (2011).

25. Pedziwiatr, M. et al. Primary tumor resection in stage IV unresectable colorectal cancer: what has changed? Medical oncology (Northwood, London, England) 34, 188, https://doi.org/10.1007/s12032-017-1047-6 (2017).

26. Clancy, C., Burke, J. P., Barry, M., Kalady, M. F. \& Calvin Coffey, J. A meta-analysis to determine the effect of primary tumor resection for stage IV colorectal cancer with unresectable metastases on patient survival. Annals of surgical oncology 21, 3900-3908, https://doi.org/10.1245/s10434-014-3805-4 (2014).

27. Cirocchi, R. et al. Non-resection versus resection for an asymptomatic primary tumour in patients with unresectable stage IV colorectal cancer. The Cochrane database of systematic reviews, CD008997, https://doi.org/10.1002/14651858.CD008997.pub2 (2012).

28. Tarantino, I. et al. Prognostic Relevance of Palliative Primary Tumor Removal in 37,793 Metastatic Colorectal Cancer Patients: A Population-Based, Propensity Score-Adjusted Trend Analysis. Annals of surgery 262, 112-120, https://doi.org/10.1097/ SLA.0000000000000860 (2015).

29. Nitsche, U. et al. Meta-analysis of outcomes following resection of the primary tumour in patients presenting with metastatic colorectal cancer. The British journal of surgery, https://doi.org/10.1002/bjs.10682 (2017).

30. Lee, K. C., Ou, Y. C., Hu, W. H., Liu, C. C. \& Chen, H. H. Meta-analysis of outcomes of patients with stage IV colorectal cancer managed with chemotherapy/radiochemotherapy with and without primary tumor resection. OncoTargets and therapy 9 , 7059-7069, https://doi.org/10.2147/OTT.S112965 (2016).

31. Faron, M. et al. Is primary tumour resection associated with survival improvement in patients with colorectal cancer and unresectable synchronous metastases? A pooled analysis of individual data from four randomised trials. European journal of cancer 51, 166-176, https://doi.org/10.1016/j.ejca.2014.10.023 (2015).

\section{Acknowledgements}

We thank the help from members of our institutes in supporting performance of this study. This study was supported by the National Natural Science Fund of China (Grant No. 81700208 and Grant No. 31971166) and Natural Science Fund of Hubei Province (Grant No. 2016CFB253). 


\section{Author contributions}

Dedong Cao worked as the supervisor and participated in processes of study design, study selection, data extraction and analysis, writing, and quality evaluation. Yongfa Zheng and Huilin Xu performed the study selection, data extraction, statistically analysis and writing. Wei Ge performed the quality evaluation. Ximing $\mathrm{Xu}$ worked as the supervisor and monitored the process of data extraction, analysis. All authors reviewed the manuscript.

\section{Competing interests}

The authors declare no competing interests.

\section{Additional information}

Supplementary information is available for this paper at https://doi.org/10.1038/s41598-019-56528-2.

Correspondence and requests for materials should be addressed to D.C. or X.X.

Reprints and permissions information is available at www.nature.com/reprints.

Publisher's note Springer Nature remains neutral with regard to jurisdictional claims in published maps and institutional affiliations.

(c) (i) Open Access This article is licensed under a Creative Commons Attribution 4.0 International License, which permits use, sharing, adaptation, distribution and reproduction in any medium or format, as long as you give appropriate credit to the original author(s) and the source, provide a link to the Creative Commons license, and indicate if changes were made. The images or other third party material in this article are included in the article's Creative Commons license, unless indicated otherwise in a credit line to the material. If material is not included in the article's Creative Commons license and your intended use is not permitted by statutory regulation or exceeds the permitted use, you will need to obtain permission directly from the copyright holder. To view a copy of this license, visit http://creativecommons.org/licenses/by/4.0/.

(C) The Author(s) 2019 